\title{
Measurement and Modeling of Clemastine Fumarate (Antihistamine Drug) Solubility in Supercritical Carbon Dioxide
}

Gholamhossein Sodeifian ( $\sim$ sodeifian@kashanu.ac.ir)

University of Kashan

Chandrasekhar Garlapati

Puducherry Technological University

Fariba Razmimanesh

University of Kashan

Marziehsadat Ghanaat-Ghamsari

University of Kashan

\section{Research Article}

Keywords: Clemastine fumarate, Solubility, Empirical models, New cluster solvation model

Posted Date: June 21st, 2021

DOI: https://doi.org/10.21203/rs.3.rs-620604/v1

License: (9) This work is licensed under a Creative Commons Attribution 4.0 International License.

Read Full License

Version of Record: A version of this preprint was published at Scientific Reports on December 1st, 2021.

See the published version at https://doi.org/10.1038/s41598-021-03596-y. 


\title{
Measurement and Modeling of Clemastine Fumarate (Antihistamine Drug) Solubility in Supercritical Carbon Dioxide
}

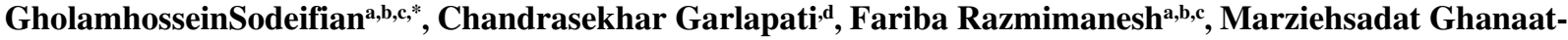 \\ Ghamsaria,b,c \\ ${ }^{a}$ Department of Chemical Engineering, Faculty of Engineering, University of Kashan, Postal Code: 87317-53153, Kashan, Iran. \\ ${ }^{b}$ Laboratory of Supercritical Fluids and Nanotechnology, University of Kashan, Postal Code: 87317-53153, Kashan, Iran. \\ ${ }^{c}$ Modeling and Simulation Centre, Faculty of Engineering, University of Kashan, Postal Code: 87317-53153, Kashan, Iran \\ ${ }^{d}$ Department of Chemical Engineering,Puducherry Technological University, Puducherry- 605014, India \\ *Corresponding author. Tel.: +983155912406; fax: +983155912424. \\ E-mail address: sodeifian@kashanu.ac.ir (G. Sodeifian)
}

\begin{abstract}
The solubilities of clemastine fumarate in supercritical carbon dioxide $\left(\mathrm{ScCO}_{2}\right)$ were measured for the first time at temperature (308 to $338 \mathrm{~K}$ ) and pressure (12 to $27 \mathrm{MPa}$ ). The measured solubilities were reported in terms of mole faction and it is ranged from $1.61 \times 10^{-6}$ to $9.41 \times 10^{-6}$. Various models were used to correlate the data. The efficacy of the models was quantified with corrected Akaike's information criterion (AICc). A new cluster salvation model was derived to correlate the solubility data. The new model was able to correlate the data and deviation was $10.3 \%$ in terms of average absolute relative deviation (AARD). Furthermore, the measured solubilities were also correlated with existing K.-W. Chen et al., cluster salvation model, equation of state (EoS) model and few density models. Among density models, Tippana and Garlapati model was observed to be the best model and corresponding AARD\% was 7.57 (corresponding $\mathrm{AIC}_{\mathrm{c}}$ is -678.88). The PengRobinson equation of state as temperature independent was able to correlate the data and deviation was $8.25 \%$ in terms of $\mathrm{AARD} \%$ (corresponding $\mathrm{AIC}_{\mathrm{c}}$ is -674.88). Moreover, thermodynamic enthalpies of clemastine fumarate were estimated.
\end{abstract}

Keywords: Clemastine fumarate, Solubility, Empirical models, New cluster solvation model. 


\section{Introduction}

Supercritical fluid technology (SFT) applications in process industry have gained significant importance. The application of carbon dioxide as supercritical fluid has several advantages over conventional techniques ${ }^{1}$ and it is designated as $\mathrm{ScCO}_{2} . \mathrm{ScCO}_{2}$ poses attractive physical properties. $\mathrm{ScCO}_{2}$ has gas like diffusivity and liquid like density with low viscosity and surface tension $^{1-2}$. Adjusting pressure and temperatures one can tune the density of $\mathrm{ScCO}_{2}$ as desired and it is exploited in various applications. Due to this tunable nature $\mathrm{ScCO}_{2}$ has been used as a solvent in various process applications. $\mathrm{ScCO}_{2}$ major applications include drug particle micronization, extraction, reactions, food processing, textile dyeing, ceramic coating, and many more ${ }^{3-7}$. To implement SFT one needs to have basic phase equilibrium information such as saturation solubility. The solubility is one of the basic information that is essential for the design and development of SFT. Drug particle micronization requires exact solubility information and in literature solubility of many drug solids in the $\mathrm{ScCO}_{2}$ is readily available, however, the solubility of clemastine fumarate is not reported ${ }^{8,9}$, therefore for the first time the solubility of clemastine fumarate in $\mathrm{ScCO}_{2}$ is reported in this work. We believe that this study may be useful in particle micronization using $\mathrm{ScCO}_{2}$. The molecular formula of clemastine fumarate is $\mathrm{C}_{21} \mathrm{H}_{26} \mathrm{Cl}$ NO. $\mathrm{C}_{4} \mathrm{H}_{4} \mathrm{O}_{4}$ and its molecular weight is 459.97 . The chemical structure is shown in figure 1.

The clemastine fumarate is a special drug and it is having specific uses. It is an antihistamine with antimuscarinic and partial sedative properties. One of its forms also acts an antileishmanial drug. It also stimulates a macrophage response to leishmania infection ${ }^{10}$. For all the medical studies (for both in vivo and in vitro) a proper dosage is very essential and this may be achieved through proper particle size ${ }^{10}$. Therefore, present study may be useful in particle micronization using $\mathrm{ScCO}_{2}$. Experimental solubility data at each pressure and temperature is very difficult therefore we need a proper model to generate the solubility data. Solubility models are classified into five types. Among them quite simple and useful are equation of sate models, density models and mathematical models ${ }^{11}$.

The main objectives of the present work are in two stages, in the first stage we determine solubility of clemastine fumarate and in the second stage we developed a new cluster solubility 
model. The proposed model is compared with existing cluster salvation model. furthermoe, few density models and equation of state model are evaluated.

\section{Experimental}

\subsection{Materials}

Gaseous $\mathrm{CO}_{2}$ (purity > 99.9\%) was obtained from Fadak company, Kashan (Iran), clemastine fumarate (CAS Number: 14976-57-9, purity > 99\%) was obtained from Amin Pharma company. Methanol (CAS No. 67-56-1, purity > 99.9\%) was obtained from Sigma Aldrich company. Table 1 indicates all the information about the chemicals utilized in this work.

\subsection{Experiment details}

Figure 2 shows the line diagram of the equipment used in the study. More details about the solubility measuring device have been presented in our earlier studies ${ }^{12-30}$. However, a brief outline of the same is presented in this section. This measuring methodology may be classified as an isobaric-isothermal method ${ }^{31}$. Each reading was reported by controlling temperature and pressures at desired values within $\pm 0.1 \mathrm{~K}$ and $\pm 0.1 \mathrm{MPa}$ precision, respectively. For each experiment about $1 \mathrm{~g}$ of clemastine fumarate drug was used. The attainment of equilibrium was observed in $60 \mathrm{~min}$. After equilibrium saturated $\mathrm{ScCO}_{2}$ sample $(600 \mu \mathrm{L})$ was collected via 2-status 6-way port valve in a methanol preloaded vial. Once sample was collected, the port valve was washed with $1 \mathrm{ml}$ methanol. Thus, the total saturation solution obtained was $5 \mathrm{ml}$. Each measurement was repeated thrice and average readings were reported. For calculations the following formulas were used [1230].

$y_{2}=\frac{n_{\text {drug }}}{n_{\text {drug }}+n_{\mathrm{CO}_{2}}}$

where $n_{\text {solute }}$ is the moles of the drug, and $n_{\mathrm{CO}_{2}}$ is the moles of $\mathrm{CO}_{2}$ in the sampling loop.

Further, we quantify moles of drug and moles of $\mathrm{CO}_{2}$ as

$$
\begin{gathered}
n_{\text {solute }}=\frac{C_{s} \cdot V_{S}}{M_{S}} \\
n_{\mathrm{CO}_{2}}=\frac{V_{1} \cdot \rho}{M_{\mathrm{CO}_{2}}}
\end{gathered}
$$


where $C_{S}$ is the drug concentration in saturated sample vial in $\mathrm{g} / \mathrm{L}$. The volume of sampling loop is $\mathrm{V}_{\mathrm{s}}(\mathrm{L})=5 \times 10^{-3} \mathrm{~m}^{3}$ and vial collection is $\mathrm{V}_{1}(\mathrm{~L})=600 \times 10^{-6} \mathrm{~m}^{3}$. The $M_{s}$ and $M_{\mathrm{CO}_{2}}$ are the molecular weight of drug and $\mathrm{CO}_{2}$, respectively. Solubility is also described as

$$
S=\frac{C_{S} V_{s}}{V_{1}}
$$

The relation between $\mathrm{S}$ and $y_{2}$ is explained as

$$
S=\frac{\rho M_{s}}{M_{\mathrm{CO}_{2}}} \frac{y_{2}}{1-y_{2}}
$$

A UNICO-4802 (model) spectrophotometer (UV-Visible) (Model UNICO-4802) has been used for the measurements of clemastine fumarate solubility. Samples collected for analysis in methanol solvent was analyzed at $270 \mathrm{~nm}$.

\section{Models}

In this section, a brief note about the exiting density models and their mathematical form werepresented.

\subsection{Existing empirical and semi-empirical models}

3.1.1. Alwi-Garlapati model ${ }^{32}$. It is a semi-empirical model. It has three parameters. According to this, solubility is represented as a function of reduced temperature and reduced density and it is mathematically stated as

$$
y_{2}=\frac{1}{\rho_{r} T_{r}} \exp \left(A_{1}+\frac{A_{2}}{T_{r}}+A_{3} \rho_{r}\right)
$$

Where $A_{1}-A_{3}$ are model constants.

3.1.2. Bartel et al., model ${ }^{33}$. It is based on enhancement factor concept and it has three parameters. According to this, solubility is represented as a function of pressure, temperature and density and it is mathematically stated as 
$\ln \left(\frac{y_{2} P}{P_{r e f}}\right)=B_{1}+\frac{B_{2}}{T}+B_{3}\left(\rho-\rho_{r e f}\right)$

Where $B_{1}-B_{3}$ are model constants. From parameter $B_{2}$ one can estimate sublimation enthalpy using the relation, $\Delta_{\text {sub }} H=-B_{2} R$ in which $R$ is universal gas constant.

3.1.3. Bian et al., model ${ }^{34}$. It is a five parameter model. It is an empirical model and it is mathematically stated as

$$
y_{2}=\rho_{1}^{\left(D_{1}+D_{23} \rho_{1}\right)} \exp \left(D_{3} / T+D_{4} \rho_{1} / T+D_{5}\right)
$$

Where $D_{3}-D_{5}$ are model constants.

3.1.4. Chrastil model ${ }^{35}$. It is a three parameter model. It is a semi empirical model and it is mathematically stated as

$$
c_{2}=\rho_{1}^{\kappa} \exp \left(E_{1}+\frac{E_{2}}{T}\right)
$$

Where $\kappa, E_{1}$ and $E_{2}$ are model constants.

In terms of mole fraction it is mathematically stated as

$$
y_{2}=\frac{\left(\rho_{1}\right)^{\kappa-1} \exp \left(E_{1}+\frac{E_{2}}{T}\right)}{\left[1+\left(\rho_{1}\right)^{\kappa-1} \exp \left(E_{1}+\frac{E_{2}}{T}\right)\right]}
$$

3.1.5. Reformulated Chrastilmodel ${ }^{36,37}$. It is also a three parameter model. It is a semi-empirical model and it is mathematically stated as

$$
y_{2}=\left(\frac{R T \rho_{1}}{M_{C F} f^{\bullet}}\right)^{\kappa^{\prime}-1} \exp \left(F_{1}+\frac{F_{2}}{T}\right)
$$

Where $\kappa^{\prime}, F_{1}$ and $F_{2}$ are model constants. 
3.1.6. Garlapati-Madras model ${ }^{38}$. It is a five parameter model. It is a mathematical model and it is mathematically stated as

$$
\ln \left(y_{2}\right)=G_{1}+\left(G_{2}+G_{3} \rho_{1}\right) \ln \left(\rho_{1}\right)+\frac{G_{4}}{T}+G_{5} \ln \left(\rho_{1} T\right)
$$

Where $G_{1}-G_{5}$ are model constants

3.1.7. Mendez-Teja model (MT model) $)^{39}$. It is a semi-empirical model and it has three parameters. It is mathematically stated as

$$
T \ln \left(y_{2} P\right)=H_{1}+H_{2} \rho+H_{3} T
$$

Where $H_{1}-H_{3}$ are model constants.

Eq. (12) is used in checking self-consistency of the measured solubility data. Accordingly, all the data points lie on a line when they plotting $T \ln \left(y_{2} P\right)-H_{3} T$ vs. $\rho_{1}$.

3.1.8. Sodefian et al., model ${ }^{40}$. It is a mathematical model and it has six parameters and it is mathematically stated as

$$
\ln \left(y_{2}\right)=I_{1}+\frac{I_{2} P^{2}}{T}+I_{3} \ln \left(\rho_{1} T\right)+I_{4}\left(\rho_{1} \ln \left(\rho_{1}\right)\right)+I_{5} P \ln (T)+I_{6} \frac{\ln \left(\rho_{1}\right)}{T}
$$

Where $I_{1}-I_{9}$ are model constants

3.1.9. Tippana-Garlapati model ${ }^{9}$. It is based on degree of freedom. It is a six parameter model.It is an empirical model and it is mathematically stated as

$$
y_{2}=\left(J_{1}+J_{2} P_{r}+J_{3} P_{r}^{2}\right) T_{r}^{2}+\left(J_{4}+J_{5} P_{r}+J_{6} P_{r}^{2}\right)
$$

Where $J_{1}-J_{6}$ are model constants.

3.1.9. Mahesh-Garlapati model ${ }^{11}$. It is based on degree of freedom. It is a three parameter model. It is an empirical model and it is mathematically stated as

$$
y_{2}=\exp \left(K_{1}+K_{2} \rho_{r} T_{r}+K_{3} \rho_{r} T_{r}^{3}\right)
$$




\subsection{Equation of state (EoS) model}

The solubility of clemastine fumarate drug, $i$ (solute), in a supercritical carbon dioxide, $j$ (solvent), is expressed as ${ }^{41}$

$$
\mathrm{y}_{\mathrm{i}}=\frac{p_{i}^{S} \hat{\phi}_{i}^{S}}{P \hat{\phi}_{i}^{S C C O_{2}}} \exp \left[\frac{\left(P-p_{i}^{S}\right) V_{i}}{R T}\right]
$$

Where $p_{i}^{s}$ is solute sublimation pressure; T, $\mathrm{P}$ are system temperature and pressures, respectively; $V_{i}$ is solute molar volume; $R$ is the universal gas constant. The fugacity coefficient of the pure solute at saturation $\left(\hat{\phi}_{i}^{S}\right)$ is usually taken to be unity. In this work, $\hat{\phi}_{i}{ }_{\mathrm{ScO}}$ is the fugacity coefficient

of the solute in the solvent phase. $\hat{\phi}_{i}{ }^{\mathrm{CCO}_{2}}$ is calculated using Peng-Robinson (PR) EoS along with two parameter van der Waals mixing rule (vdW2 $)^{42}$. The expression used for calculation of $\hat{\phi}_{i}{ }^{\mathrm{cCO}_{2}}$ is obtained from the following basic thermodynamic relation ${ }^{43}$.

$$
\ln \left(\hat{\varphi}_{i}^{S C C O_{2}}\right)=\frac{1}{R T} \int_{v}^{\infty}\left[\left(\frac{\partial P}{\partial N_{i}}\right)_{T, V, N_{j}}-\frac{R T}{v}\right] d v-\ln Z
$$

The general PREoS form [42] is

$$
P=\frac{R T}{V-b}-\frac{a(T)}{V(V+b)+b(V-b)}
$$

Where $\mathrm{P}$ is the pressure, $\mathrm{R}$ is the universal gas constant, $\mathrm{T}$ is the temperature and $\mathrm{V}$ is the molar volume. The pure component parameters $a$ and $b$ are

$$
\begin{aligned}
& a(T)=0.45724 \frac{R^{2} T_{c}^{2}}{P_{c}} \alpha\left(T_{r}, \omega\right) \\
& \alpha\left(T_{r}, \omega\right)=\left[1+\left(0.37464+1.5422 \omega-0.26992 \omega^{2}\left(1-\sqrt{T_{r}}\right)\right)\right]^{2} \\
& b=0.07780 \frac{R T_{c}}{P_{c}}
\end{aligned}
$$


The expression for $\hat{\phi}_{i} \mathrm{ScCO}_{2}$ is:

$$
\begin{aligned}
& \ln \left(\hat{\phi}_{\mathrm{i}}^{S c F}\right)=\frac{\hat{b}}{b}(\mathrm{Z}-1)-\ln \left[\mathrm{Z}\left(1-\frac{b}{v}\right)\right]+\frac{\mathrm{a}}{(2 \sqrt{2}) b R T}\left[\frac{\hat{\mathrm{a}}}{a}-\frac{\hat{b}}{b}\right] \ln \left(\frac{Z-0.414 b}{Z+2.414 b}\right) \\
& \hat{a}=\frac{1}{n} \frac{\partial n^{2} a}{\partial n_{i}}=2 \sum x_{i} a_{i j} ; \hat{b}=\frac{\partial n b}{\partial n_{i}}=2 \sum x_{i} b_{i j}-b
\end{aligned}
$$

\subsubsection{The expressions for $\mathrm{VdW} 2$}

$$
\begin{aligned}
& a=\sum_{i} \sum_{j} x_{i} x_{j} a_{i j} \\
& b=\sum_{i} \sum_{j} x_{i} x_{j} b_{i j} \\
& a_{i j}=\left(1-k_{i j}\right) \sqrt{a_{i i} a_{j j}} \\
& b_{i j}=\left(1-l_{i j}\right) \frac{\left(b_{i i}+b_{j j}\right)}{2}
\end{aligned}
$$

The PREoS regression may be carried out either temperature independent or temperature dependent. For temperature independent regression a suitable sublimation expression is used. The general form ${ }^{44,45}$ used for the regression purpose is

$$
R \ln \left(p_{\text {sub }}\right)=\beta+\frac{\gamma}{T}+\Delta_{\text {sub }} \delta \ln \left(\frac{T}{298.15}\right)
$$

The regression directly results in binary interaction parameters along with sublimation pressure expression coefficients $\left(\beta / R, \gamma / R\right.$ and $\left.\Delta_{\text {sub }} \delta / R\right)$ and from parameters $\gamma$ and $\Delta_{\text {sub }} \delta$ we can estimate sublimation pressure. The expression for sublimation enthalpy is

$$
\Delta_{\text {sub }} H=-\gamma+\Delta_{\text {sub }} \delta T
$$

\subsection{New cluster model}

This model is an extension to K.-W. Chen et al., model ${ }^{46}$. According to the model the formation of solvate complex $A B_{\kappa}$ is a due to the equation reaction mention in eq.(28), where $\mathrm{A}$ is solute and $B$ is supercritical fluid.

$$
A+\kappa^{\prime \prime} B \Leftrightarrow A B_{\kappa}
$$


It is an equilibrium reaction and at equilibrium the following condition is satisfied.

$\sum v_{i} \bar{F}_{i}\left(T, P, z_{i}\right)=0$

Where $\sum$ is summation; $v$ and $\bar{F}$ are stoichiometric coefficient and partial molar Gibbs energy, respectively.

In general the partial molar Gibbs energy for species is written as

$$
\bar{F}_{i}\left(T, P, z_{i}\right)=\bar{F}_{i}^{o}\left(T, P^{o}, z_{i}^{o}\right)+\left(\bar{F}_{i}\left(T, P, z_{i}\right)-\bar{F}_{i}^{o}\left(T, P^{o}, z_{i}^{o}\right)\right)
$$

Where $P^{o}$ and $z_{i}^{o}$ are reference state pressure and composition of species i. In this work, similar to that of K.-W. Chen et al. model, reference pressure is taken as critical pressure of the supercritical fluid. Similar to K.-W. Chen et al., model ${ }^{46}$, the expression for the equilibrium in terms of fugacity coefficients is

$\ln \left(\frac{z_{A B_{\kappa}}}{z_{B}^{\kappa^{\prime \prime}}}\right)=k \ln \left(\frac{\hat{\phi}_{B}\left(T, P, z_{B}\right) P}{\phi_{B}\left(T, P_{c, S c f}\right) P_{c, s c f}}\right)+\frac{V_{s}\left(P-P_{c, s c f}\right)}{R T}-\ln \left(\frac{\hat{\phi}_{A B_{\kappa}}\left(T, P, z_{A B_{\kappa}}\right) P}{\phi_{A B_{\kappa}}\left(T, P_{c, s c f}\right) P_{c, s c f}}\right)-\frac{\Delta F^{r x n}\left(T, P_{c, s c f}\right)}{R T}$

where $\Delta F^{r x n}\left(T, P_{c, s c f}\right)$ is the change in Gibbs energy as a result of formation of solvate complex.

The model has two parameters $\kappa^{\prime \prime}$ and $\Delta F^{r x n}\left(T, P_{c, s c f}\right)$. In this work we have used the following temperature dependent general from ${ }^{47}$ in place of $\Delta F^{r x n}\left(T, P_{c, s c f}\right)$

$$
\Delta F^{r x n}\left(T, P_{c, s c f}\right)=a^{\prime}+b^{\prime} T \ln (T)+c^{\prime} T
$$

Thus the final model has $\kappa^{\prime \prime}, \mathrm{a}, \mathrm{b}$ and c (four adjustable parameters).

The eq.(31) is further simplified with the help of Taylor series on left hand side

$$
\ln \left(\frac{z_{A B_{\kappa}}}{1-\kappa^{\prime \prime} z_{A B_{\kappa}}}\right)=k \ln \left(\frac{\hat{\phi}_{B}\left(T, P, z_{B}\right) P}{\phi_{B}\left(T, P_{c, s c f}\right) P_{c, s c f}}\right)+\frac{V_{s}\left(P-P_{c, s c f}\right)}{R T}-\ln \left(\frac{\hat{\phi}_{A B_{\kappa}}\left(T, P, z_{A B_{\kappa}}\right) P}{\phi_{A B_{\kappa}}\left(T, P_{c, s c f}\right) P_{c, s c f}}\right)-\frac{\Delta F^{r x n}\left(T, P_{c, s c f}\right)}{R T}
$$

The experimental solubility and cluster mole fractions are related as ${ }^{48}$ follows 


$$
y=z_{A B_{\kappa}} /\left(1+\kappa^{\prime \prime} z_{A B_{\kappa}}\right)
$$

The fugacity coefficient of the components and mixtures are evaluated with any cubic equation of state. However, in this work we have followed the K.-W. Chen et al., model, where PREoS had shown good results. For fugacity coefficient calculations we need mixture properties and they are calculated with the help of cluster and supercritical fluids. More details about these can be seen elsewhere ${ }^{49}$.

The cluster obeys the following mixing rules for volume and energy parameters

$$
\begin{aligned}
& b_{A B_{\kappa}}=k^{\prime \prime} b_{B}+b_{A} \\
& a_{A B_{\kappa}}=\left[k^{\prime \prime}\left(a_{B} b_{B}\right)^{0.5}+\left(a_{A} b_{A}\right)^{0.5}\right]^{2} / b_{A B_{\kappa \kappa}}
\end{aligned}
$$

More details about PREoS, fugacity coefficient of pure component and mixture can be seen in section 3.2 and literature ${ }^{48,49}$

The final expression for the solubility is

$$
y=\frac{\exp \left[\kappa^{\prime \prime} \ln \left(\frac{\hat{\phi}_{B}\left(T, P, z_{B}\right) P}{\phi_{B}\left(T, P_{c, S c f}\right) P_{c, s c f}}\right)+\frac{V_{s}\left(P-P_{c, s c f}\right)}{R T}-\ln \left(\frac{\hat{\phi}_{A B_{\kappa}}\left(T, P, z_{A B_{\kappa}}\right) P}{\phi_{A B_{\kappa}}\left(T, P_{c, s c f}\right) P_{c, s c f}}\right)-\frac{\left(a^{\prime}+b^{\prime} T \ln (T)+c^{\prime} T\right)}{R T}\right]}{1+2 \kappa^{\prime \prime} \exp \left[\kappa^{\prime \prime} \ln \left(\frac{\hat{\phi}_{B}\left(T, P, z_{B}\right) P}{\phi_{B}\left(T, P_{c, S c f}\right) P_{c, s c f}}\right)+\frac{V_{s}\left(P-P_{c, s c f}\right)}{R T}-\ln \left(\frac{\hat{\phi}_{A B_{\kappa}}\left(T, P, z_{A B_{\kappa}}\right) P}{\phi_{A B_{\kappa}}\left(T, P_{c, s c f}\right) P_{c, s c f}}\right)-\frac{\left(a^{\prime}+b^{\prime} T \ln (T)+c^{\prime} T\right)}{R T}\right]}
$$

Hereafter it may be called as cluster model by sodeifian et al.

\subsubsection{K.-W. Chen et al., model}

Cluster model proposed by K.-W. Chen et al., is ${ }^{46}$

$$
y=\frac{\exp \left[\kappa^{\prime \prime \prime} \ln \left(\frac{\hat{\phi}_{B}\left(T, P, z_{B}\right) P}{\phi_{B}\left(T, P_{c, S c f}\right) P_{c, s c f}}\right)+\frac{V_{s}\left(P-P_{c, s c f}\right)}{R T}-\ln \left(\frac{\hat{\phi}_{A B_{\kappa}}\left(T, P, z_{A B_{\kappa}}\right) P}{\phi_{A B_{\kappa}}\left(T, P_{c, s c f}\right) P_{c, s c f}}\right)-\frac{\left(a^{\prime \prime}-b^{\prime \prime} T\right)}{R T}\right]}{1+2 \kappa^{\prime \prime \prime} \exp \left[\kappa^{\prime \prime \prime} \ln \left(\frac{\hat{\phi}_{B}\left(T, P, z_{B}\right) P}{\phi_{B}\left(T, P_{c, S c f}\right) P_{c, s c f}}\right)+\frac{V_{s}\left(P-P_{c, s c f}\right)}{R T}-\ln \left(\frac{\hat{\phi}_{A B_{\kappa}}\left(T, P, z_{A B_{\kappa}}\right) P}{\phi_{A B_{\kappa}}\left(T, P_{c, s c f}\right) P_{c, s c f}}\right)-\frac{\left(a^{\prime \prime}-b^{\prime \prime} T\right)}{R T}\right]}
$$

Where $\kappa^{\prime \prime \prime}, a^{\prime \prime}$ and $b^{\prime \prime}$ are three adjustable parameters. 
All the models mentioned in sections 3.1, 3.2 and 3.3 are evaluated with the following objective function $^{50}$.

$$
O F=\sum_{i=1}^{N}\left|y_{i}^{\exp }-y_{i}^{c a l}\right| / y_{i}^{\exp }
$$

Regression results are represented in terms of average absolute relative deviation percentage (AARD \%)

$$
A A R D \%=100 / N \sum_{i=1}^{N}\left|y_{i}^{\exp }-y_{i}^{c a l}\right| / y_{i}^{\exp }
$$

Where $N$ is number of experimental data points; $y_{i}$ is mole fraction; the superscripts $c a l$ and $\exp$ denotes the calculated and measured mole fractions, respectively.

\section{Results and discussion}

Table 1 indicates some properties of the used materials. Table 2 shows clemastine fumarate solubility in $\mathrm{ScCO}_{2}$. The density indicated in Table 2 is obtained from the NIST data base. Fig. 3 indicates the effect of pressure on various isotherms and no cross over region observed, such solubility behavior is observed for some other pharmaceutical compounds in our earlier studies ${ }^{23}$. Fig. 4 indicates the self-consistency of the measured data with MT model. The regression analysis of experimental data is carried out easily with density model, but the regression analysis of EoS model and cluster model requires critical properties of the solute and solvent. The required critical temperature, critical pressure, acentric factor and molar volume of the solute and sublimation pressure of the solute are not readily available; due to this these properties are computed with standard group contribution methods ${ }^{51-54}$. Table. 3 indicates all computed data. The empirical and semi empirical models considered in this study have shown different degree of fitting in terms of AARD\%. The regression results of various models are indicated in Tables 4, 5 and 6 . Among the existing empirical and semi-empirical models, Tippana-Garlapati model is having lower AARD\%. Chrastil model parameter $\left(E_{2}\right)$ and Reformulated Chrastil model parameter $\left(F_{2}\right)$ are used in calculating total enthalpy, from Bartel et al., model parameter $\left(B_{2}\right)$ we get sublimation enthalpy of the clemastine fumarate. Heat of solvation is obtained from the magnitude difference between total enthalpy and sublimation enthalpy. The more details about these calculations can be seen in literature ${ }^{23,30,35}$. All the computed results are reported in Table 7. EoS model is regressed in two different ways. In the first approach correlation parameter are treated as temperature dependent where as in second approach the correlation parameters are treated as temperature independent. 
From regression results (Table 5) temperature independent correlation is better than temperature dependent correlation. EoS model also provide sublimation enthalpy and it is reported in Table 7. From Table 6 the new cluster model is superior to exiting K.-W. Chen et al., model. The new model parameters ' $a$ ' 'and ' $b$ ', directly results in enthalpy change and entropy change of the cluster formation process. The positive sign for entropy change indicates an increase in disorder. The positive change in enthalpy indicates heat absorption from surroundings the by the reaction. The correlating ability of the various models are represented in Figs.(4)-(9).

The models used in correlation exercise are having varying number of parameters and the best model is obtained with the help of Akaike's information criterion (AIC) ${ }^{55-59}$. The data used in this exercise is small $(\mathrm{N}<40)$, hence corrected $\mathrm{AIC}\left(\mathrm{AIC} \mathrm{C}_{\mathrm{c}}\right)$ is used for the identifying the best model.

$$
A I C_{c}=A I C+\frac{2 N_{p}\left(N_{p}+1\right)}{N-N_{p}-1}
$$

Where AIC is $N \ln (S S E / N)+2 Q ; \mathrm{N}$ is number of experimental data points; $N_{p}$ is model parameters; SSE is error sum of squares. According to $\mathrm{AIC}_{\mathrm{c}}$ test, each model gives least value that model would be considered as the best model. Table 8 indicates computed AIC and AICc values. The least $\mathrm{AIC}_{\mathrm{c}}$ value -678.88 is seen for Tippana-Garlapati model; therefore, it is considered as the best model, however, the new cluster model has also comparable performance with the best model, the corresponding $\mathrm{AIC}_{\mathrm{c}}$ value is -678.59 . The highest $\mathrm{AIC}_{\mathrm{c}}$ value is seen for Bartel et al., model hence it is treated as poor model for clemastine fumarate.

\section{Conclusion}

Solubilities of clemastine fumarate in $\mathrm{ScCO}_{2}$ at temperatures $(\mathrm{T}=308-338 \mathrm{~K})$ and pressures $(\mathrm{P}=$ 12-27 MPa) were reported for the first time. The measured solubilities were successfully correlated with several models; however, Tippana-Garlapati model is observed to be the best model in correlating the solubility data. The correlating ability in ascending order of various models in terms of lowest $\mathrm{AIC}_{\mathrm{c}}$ values are as follows: Tippana-Garlapati model, new cluster model, PREoS as temperature independent, K.-W. Chen et al., model, Bian et al., model, Sodefian et al., model, Alwi-Garlapati model, Mahesh-Garlapati model, Chrastil model, Reformulated Chrastil model, Garlapati-Madras model, Mendez-Teja model, Bartel et al., model. The new cluster model proposed in this work may be useful for correlating solids solubility in any SCF. 


\section{Acknowledgements}

Corresponding authors would like to thank the research deputy of university of Kashan (Grant \# Pajoohaneh-1400/16) for the financial support of this project. Authors also appreciate Amin Pharma company for providing the required drug.

\section{Nomenclature}

$A_{1}-A_{3}$

$B_{1}-B_{3}$

$D_{1}-D_{5}$

$E_{1}-E_{2}$

$F_{1}-F_{2}$

$G_{1}-G_{5}$

$H_{1}-H_{3}$

$I_{1}-I_{6}$

$J_{1}-J_{6}$

$K_{1}-K_{3}$

AARD

AIC

$\mathrm{AIC}_{\mathrm{c}}$

$a_{\mathrm{ij}}$

$b_{\mathrm{ij}}$

$\mathrm{C}$

EoS

$\mathrm{H}_{\text {sol }}$

$\mathrm{H}_{\text {sub }}$

$\mathrm{H}_{\text {Total }}$

Mscf
Alwi-Garlapati parameters

Bartel model parameters

Bian et al., model parameters

Chrastil model parameters

Reformulated Chrastil model parameters

Garlapati-Madras model parameters

Mendez-Teja model parameters

Sodefian et al., model parameters

Tippana-Garlapati model parameters

Mahesh-Garlapati model parameters

Average absolute relative deviation

Akaike Information Criterion

Corrected Akaike Information Criterion

EoS energy parameter

EoS volume correction

Solubility in Chrastil model

Equation of State

Salvation enthalpy

Sublimation enthalpy

Total enthalpy

Molecular weight of supercritical fluid 


$\begin{array}{ll}N & \text { Number of data points } \\ N_{p} & \text { Number of parameters of a model } \\ P & \text { Total pressure } \\ P^{\text {sub }} & \text { Sublimation pressure } \\ \mathrm{PR} & \text { Peng-Robinson } \\ \mathrm{P}_{\mathrm{r}} & \text { Reduced pressure } \\ \mathrm{P}_{\mathrm{c}} & \text { Critical pressure } \\ \mathrm{R} & \text { Universal gas constant } \\ \mathrm{R}^{2} & \text { Square of correlation coefficient } \\ \mathrm{SSE} & \text { Sum of squares error } \\ \mathrm{T} & \text { Temperature } \\ \mathrm{T}_{\mathrm{c}} & \text { Critical temperature } \\ \mathrm{Tr} & \text { Reduced temperature } \\ \mathrm{y}_{\mathrm{i}} & \text { Solubility in mole fraction }\end{array}$

\section{Greek Symbols}

$\begin{array}{ll}\Delta & \text { Difference } \\ \hat{\phi}_{i}^{S} & \begin{array}{l}\text { Fugacity coefficient of the pure } \\ \text { substance at saturation }\end{array} \\ \hat{\phi}_{i}^{S c C O_{2}} & \begin{array}{l}\text { Solute fugacity in supercritical carbon } \\ \text { dioxide }\left(\mathrm{scCO}_{2}\right)\end{array} \\ \varpi & \text { Acentric factor } \\ \rho & \text { Density } \\ \rho_{r} & \text { Reduced density } \\ \kappa_{j i} & \text { Correlation parameter } \\ l_{j i} & \text { Correlation parameter } \\ \kappa \kappa^{\prime} \kappa^{\prime \prime} \kappa^{\prime \prime \prime} & \text { Association numbers in respective eqs. }\end{array}$

\section{Sub and}

\section{Supercripits}

$\exp$

Experimental 


$\begin{array}{ll}\text { cal } & \text { Calculated } \\ \mathrm{j} & \text { Solvent } / \mathrm{ScCO}_{2} \\ \mathrm{i} & \text { Solute/drug } \\ \mathrm{c} & \text { Critical } \\ \mathrm{r} & \text { Reduced }\end{array}$

\section{REFERENCES}

1. Subramaniam, B., Rajewski, R.A. \& Snavely, K. Pharmaceutical processing with supercritical carbon dioxide, J. Pharmacentical. Sci. 86, 885-890. https://doi.org/10.1021/js9700661(1997).

2. Hitchen, S. \& Dean, J. Properties of supercritical fluids. in: Applications of Supercritical Fluids in Industrial Analysis,1-11(Springer, 1993).

3. Reverchon, E., De Marco, I. \& Torino, E. Nanoparticles production by supercriticalantisolvent precipitation:a general interpretation, J.Supercrit. Fluids $\mathbf{4 3}, 126-$ 138. https://doi.org/10.1016/j.supflu.2007.04.013 (2007).

4. Sodeifan, G. \& Sajadian, S. A. Solubility measurement and preparation of nanoparticles of an anticancer drug (Letrozole) using rapid expansion of supercritical solutions with solid cosolvent (RESS-SC). J. Supercrit. Fluids 133, 239-252. https://doi.org/10. 1016/j.supfu.2017.10.015 (2018).

5. Sodeifan, G., Ardestani, N. S., Sajadian, S. A. \& Panah, H. S. Experimental measurements and thermodynamic modeling of Coumarin-7 solid solubility in supercritical carbon dioxide: Production of nanoparticles via RESS method. Fluid Phase Equilib. 483, 122143. https://doi.org/10.1016/j.fuid.2018.11.006 (2019).

6. Ardestani, N.S., Sodeifian,G. \& Sajadian,S.A preparation of phthalocyanine green nano pigment using supercritical $\mathrm{CO}_{2}$ gas antisolvent (GAS): Experimental and modeling, Heliyon, $\boldsymbol{6}$, e049476. https://doi.org/10.1016/j.heliyon.2020.e04947(2020)

7. Sodeifan, G., Sajadian, S. A. \& Daneshyan, S. Preparation of Aprepitant nanoparticles (efcient drug for coping with the efects of cancer treatment) by rapid expansion of supercritical solution with solid cosolvent (RESS-SC). J. Supercrit. Fluids 140, 72-84. https://doi.org/10.1016/j.supfu.2018.06.009 (2018).

8. Zordi, N.D., Kikic, I., Moneghini, M. \& Solinas, D. Solubility of pharmaceutical compounds in supercritical carbon dioxide, J. Supercrit. Fluids 66, 16-22. https://doi.org/10.1016/j.supflu.2011.09.018 (2012).

9. Reddy, T. A. \& Garlapati, C. Dimensionless empirical model to correlate pharmaceutical compound solubility in supercritical carbon dioxide. Chem. Eng. Technol. 42, 2621-2630. https://doi.org/10.1002/ceat.201900283 (2019).

10. Mina, J. G. M et al. Antileishmanial Chemotherapy through Clemastine Fumarate Mediated Inhibition of the Leishmania Inositol Phosphorylceramide Synthase: ACS Infect. Dis. 7, 47-63. https://doi.org/10.1021/acsinfecdis.0c00546 (2021).

11. Mahesh G \& Garlapati, C., Modelling of solubility of some parabens in supercritical carbon 
dioxide and new correlations, Arab. J. Sci. Eng., 1-13

https://doi.org/10.1007/s13369-021-05500-2 (2021).

12. Sodeifan, G., Ardestani, N. S. \& Sajadian, S. A. Solubility measurement of a pigment (Phthalocyanine green) in supercritical carbon dioxide: Experimental correlations and thermodynamic modeling. Fluid Phase Equilib. 494, 61-73. https://doi.org/10.1016/j.fuid. 2019.04.024 (2019).

13. Sodeifan, G., Drakhsheshpoor, R. \& Sajadian, S. A. Experimental study and thermodynamic modeling of Esomeprazole (protonpump inhibitor drug for stomach acid reduction) solubility in supercritical carbon dioxide. J. Supercrit. Fluids 154, 104606. https://doi.org/10. 1016/j.supfu.2019.104606 (2019).

14. Sodeifan, G., Hazaveie, S. M., Sajadian, S. A. \& Saadati Ardestani, N. Determination of the solubility of the repaglinide drug in supercritical carbon dioxide: Experimental data and thermodynamic modeling. J. Chem. Eng. Data 64, 5338-5348. https://doi. org/10.1021/acs.jced.9b00550 (2019).

15. Sodeifan, G., Sajadian, S. A. \& Ardestani, N. S. Optimization of essential oil extraction from Launaea acanthodes Boiss: Utilization of supercritical carbon dioxide and cosolvent. J. Supercrit. Fluids 116, 46-56. https://doi.org/10.1016/j.supfu.2016.05.015 (2016).

16. Sodeifan, G., Sajadian, S. A. \& Ardestani, N. S. Experimental optimization and mathematical modeling of the supercritical fuid extraction of essential oil from Eryngium billardieri: Application of simulated annealing (SA) algorithm. J. Supercrit. Fluids 127, 146-157. https://doi.org/10.1016/j.supfu.2017.04.007 (2017).

17. Sodeifan, G. \& Sajadian, S. A. Investigation of essential oil extraction and antioxidant activity of Echinophora platyloba DC. using supercritical carbon dioxide. J. Supercrit. Fluids 121, 52-62. https://doi.org/10.1016/j.supfu.2016.11.014 (2017).

18. Sodeifan, G., Sajadian, S. A. \& Daneshyan, S. Preparation of Aprepitant nanoparticles (efficient drug for coping with the effects of cancer treatment) by rapid expansion of supercritical solution with solid cosolvent (RESS-SC). J. Supercrit. Fluids 140, 72-84. https://doi.org/10.1016/j.supfu.2018.06.009 (2018).

19. Sodeifan, G., Sajadian, S. A., Razmimanesh, F. \& Ardestani, N. S. A comprehensive comparison among four diferent approaches for predicting the solubility of pharmaceutical solid compounds in supercritical carbon dioxide. Korean J. Chem. Eng. 35, 2097-2116. https://doi.org/10.1007/s11814-018-0125-6 (2018).

20. Sodeifan, G., Sajadian, S. A. \& Derakhsheshpour, R. Experimental measurement and thermodynamic modeling of Lansoprazole solubility in supercritical carbon dioxide: Application of SAFT-VR EoS. Fluid Phase Equilib. 507, 112422. https://doi.org/10.1016/j. fuid.2019.112422 (2020).

21. Sodeifan, G., Razmimanesh, F., Sajadian, S. A. \& Panah, H. S. Solubility measurement of an antihistamine drug (loratadine) in supercritical carbon dioxide: Assessment of qCPA and PCP-SAFT equations of state. Fluid Phase Equilib. 472, 147-159. https:// doi.org/10.1016/j.fuid.2018.05.018 (2018).

22. Sodeifan, G., Nasri, L., Razmimanesh, F. \& Abadian, M. Measuring and modeling the solubility of an antihypertensive drug (losartan potassium, Cozaar) in supercritical carbon dioxide. J. Mol. Liq. 331, 115745. https://doi.org/10.1016/j.molliq.2021.115745 (2021).

23. Sodeifan, G., Garlapati, C., Razmimanesh, F. \& Sodeifan, F. Solubility of amlodipine besylate (calcium channel blocker drug) in supercritical carbon dioxide: Measurement and correlations. J. Chem. Eng. Data 66, 1119-1131. https://doi.org/10.1021/acs.jced. 0c00913 
(2021).

24. Sodeifan, G., Razmimanesh, F., Ardestani, N. S. \& Sajadian, S. A. Experimental data and thermodynamic modeling of solubility of Azathioprine, as an immunosuppressive and anticancer drug, in supercritical carbon dioxide. J. Mol. Liq. 299, 112179. https:// doi.org/10.1016/j.molliq.2019.112179 (2020).

25. Sodeifan, G., Alwi, R. S., Razmimanesh, F. \& Tamura, K. Solubility of quetiapine hemifumarate (antipsychotic drug) in supercritical carbon dioxide: Experimental, modeling and hansen solubility parameter application. Fluid Phase Equilib. 537, 113003. https://doi.org/10. 1016/j.fuid.2021.113003 (2021).

26. Sodeifan, G. \& Sajadian, S. A. Experimental measurement of solubilities of sertraline hydrochloride in supercriticalcarbon dioxide with/without menthol: Data correlation. $J$. Supercrit. Fluids 149, 79-87. https://doi.org/10.1016/j.supfu.2019.03.020 (2019).

27. Sodeifan, G., Sajadian, S. A. \& Ardestani, N. S. Determination of solubility of Aprepitant (an antiemetic drug for chemotherapy) in supercritical carbon dioxide: Empirical and thermodynamic models. J Supercrit. Fluids 128, 102-111. https://doi.org/10.1016/j. supfu.2017.05.019 (2017).

28. Sodeifan, G., Sajadian, S. A. \& Razmimanesh, F. Solubility of an antiarrhythmic drug (amiodarone hydrochloride) in supercritical carbon dioxide: Experimental and modeling. Fluid Phase Equilib. 450, 149-159. https://doi.org/10.1016/j.fuid.2017.07.015 (2017).

29. Sodeifan, G., Sajadian, S. A., Razmimanesh, F., \& Hazaveie, S.M. Solubility of Ketoconazole (antifungal drug) in SC-CO2 for binary and ternary systems: measurements and empirical. Scientifc Reports 11, 7546. https://doi.org/10.1038/s41598-021-87243-6 (2021).

30. Sodeifan, G., Garlapati, C., Razmimanesh, F. \& Sodeifan, F. The solubility of Sulfabenzamide (an antibacterial drug) in supercritical carbon dioxide: Evaluation of a new thermodynamic model. J. Mol. Liq. 335, 116446. https://doi.org/10.1016/j.molliq.2021.116446 (2021).

31. Peper, S.,Fonseca,J.M.S. \& Dohrn,R High-pressure fluidphase equilibria: Trends, recent developments, and systems investigated (2009-2012), Fluid Phase Equilib. 484, 126-224. https://doi.org/10.1016/j.fluid.2018.10.007 (2019).

32. Alwi, R.S. \& Garlapati,C. A new semi empirical model for the solubility of dyestuffs in supercritical carbon dioxide, Chem. Pap. 75, 2585-2595. https://doi.org/10.1007/s11696020-01482-x (2021).

33. Bartle, K. D., Cliford, A. A., Jafar, S. A. \& Shilstone, G. F. Solubilities of solids and liquids of low volatility in supercritical carbon dioxide. J. Phys. Chem. Ref. Data 20, 713-756. https://doi.org/10.1063/1.555893 (1991).

34. Bian, X.- Q., Zhang,Q., Du, Z.-M., Chen, J. \& Jaubert, J.N. A five-parameter empirical model for correlating the solubility of solid compounds in supercritical carbon dioxide, Fluid Phase Equilib. 411, 74-80. https://doi.org/10.1016/j.fluid.2015.12.017(2016).

35. Chrastil, J. Solubilities of solids and liquids in supercritical gases, J. Phys. Chem. 86, 30163021. https://doi.org/10.1021/j100212a041(1982).

36. Garlapati, C. \& Madras, G. Solubilities of Palmitic and steric fatty acids in supercritical carbon dioxide, J. Chem. Thermodyn. 42, 193-197.

http://dx.doi.org/10.1016/j.jct.2009.08.001(2010).

37. Garlapati, C. \& Madras, G. Solubilities of solids in supercritical fluids using dimensionally consistent modified solvate complex models, Fluid Phase Equilib. 283, 97-101. 
https://doi.org/10.1016/j.fluid.2009.05.013(2009).

38. Garlapati, C. \& Madras, G.New empirical expressions to correlate solibilities of solids in supercritical carbon dioxide, Thermochimica Acta 500, 123-127. https://doi.org/10.1016/j.tca.2009.12.004(2010).

39. Méndez-Santiago, J. \& Teja, A. S. Te solubility of solids in supercritical fuids. Fluid Phase Equilib. 158, 501-510. https://doi.org/ 10.1016/S0378-3812(99)00154-5 (1999).

40. Sodeifan, G., Razmimanesh, F. \& Sajadian, S. A. Solubility measurement of a chemotherapeutic agent (Imatinib mesylate) in supercritical carbon dioxide: Assessment of new empirical model. J. Supercrit. Fluids 146, 89-99. https://doi.org/10.1016/j.supfu. 2019.01.006 (2019).

41. Sandler, S.I. Chemical,Biochemical and Engineering Thermodynamics, 664-666(Wiley, 1996).

42. Peng, D.-Y. \& Robinson, D. B. A new two-constant equation of state. Ind. Eng. Chem. Fundam. 15, 59-64. https://doi.org/10.1021/i160057a011 (1976).

43. Prausnitz, J. M., Lichtenthaler, R. N.. \& De Azevedo, E. G. Molecular thermodynamics of fluidphase equilibria,33-34 (Mcgraw-hill, 2001).

44. Garlapati.C. \& Madras,G. Temperature independent mixing rules to correlate the solubilities of antibiotics and anti-inflammatory drugs in $\mathrm{SCCO}_{2}$, Thermochimica Acta 496, 54-58. https://doi.org/10.1016/j.tca.2009.06.022 (2009).

45. Sodeifan, G., Garlapati, C., Razmimanesh, F. \& Sodeifan, F. Solubility of 2,4,7-Triamino6-phenylpteridine (Triamterene, Diuretic Drug) in Supercritical Carbon Dioxide:

Experimental Data and Modeling. J. Chem. Eng. Data 65, 4406-4416. https://doi.org/ 10.1021/acs.jced.0c00268 (2020).

46. Chen, K.-W.,Tang, M. \& Chen Y.-P. Calculation of solid solubility in supercritical fluids using a simplified cluster salvation model, Fluid Phase Equilib. 234, 169-186, https://doi.org/ 10.1016/S0378-3812(03)00350-9(2003).

47. Rajaram,J. \& Kuriacose, J.C. Chemical thermodynamics Classical, statistical and irreversible,218-219(Pearson Dorling Kindersley , 2013).

48. Zong,M.,Han,B.Ke,.J.,Yan,H. \&Peng, D.Y. A model for correlating solubility of of solids in supercritical $\mathrm{CO}_{2}$, Fluid Phase Equilib. 146, 93-102. https://doi.org/10.1016/S03783812(98)00207-6 (1998).

49. Lemert,R.M. \& Johnston ,K.P. Chemical complexing agents for enhanced solubilities in supercritical fluid carbon dioxide, Ind. Eng. Chem. Res. 30, 1222-1231. https://doi.org/10.1021/ie00054a024 (1991).

50. Valderrama, J.O. \& Alvarez, V.H. Correct way of reporting results when modelling supercritical phase equilibria using equations of state. Can. J. Chem. Eng. 83, 578-581. https://doi.org/10.1002/cjce.5450830323(2005).

51. Fedors, R.F. A relationship between Chemical structure and the critical temperature. Chem. Eng. Commun.16, 149-151.https://doi.org/10.1080/00986448208911092(1982)

52. Reid, R.C., Prausnitz, J.M \& Poling,B.E. The properties of gases and liquids (McGrawHill, 1988)

53. Immirzi, A. \& Perini, B. Prediction of density in organic crystals, Acta Crystall. A-Crys. 33, 216-218. https://doi.org/10.1107/S0567739477000448 (1977).

54. Lyman, W.J., Reehl, W.F. \& Rosenblatt, D.H. Handbook of chemical property estimation methods, (McGraw-Hill,1982).

55. Kletting, P. \& Glatting, G., Model selection for time-activity curves: the corrected Akaike 
information criterion and the F-test. Zeitschriftfürmedizinische Physik 19,200-206. https://doi.org/10.1016/j.zemedi.2009.05.003 (2019)

56. Burnham, K.P \& Anderson, D.R Multimodel inference understanding AIC and BIC in model selection. Sociol. Methods Res. 33, 261-304. https://doi.org/10.1177/00491 24104268644 (2004).

57. Deepitha, J., Pitchaiah, K.C., Rao, C.V.S.B., Madras,G. \& Sivaraman, N Solubilities of dialkylhydrogen phosphonates in supercritical carbon dioxide and their correlation using semi-empirical equations. Sep. Sci. Technol. 54, 1650-1660. https://doi.org/10.1080/01496395.2018.1538244 (2019).

58. Pitchaiah, K. C. et al. Experimental measurements and correlation of the solubility of N, N-dialkylamides in supercritical carbon dioxide. J. Supercrit. Fluids 143, 162-170. https://doi.org/10.1016/j.supflu.2018.08.007 (2019).

59. Lamba, N.,Narayan, R.C., Modak. J. \& Madras, G. Solubilities of 10-undecenoic acid and geraniol in supercritical carbon dioxide, J. Supercrit. Fluids 107, 384-391. https://doi.org/10.1016/j.supflu.2015.09.026 (2016). 
Figures

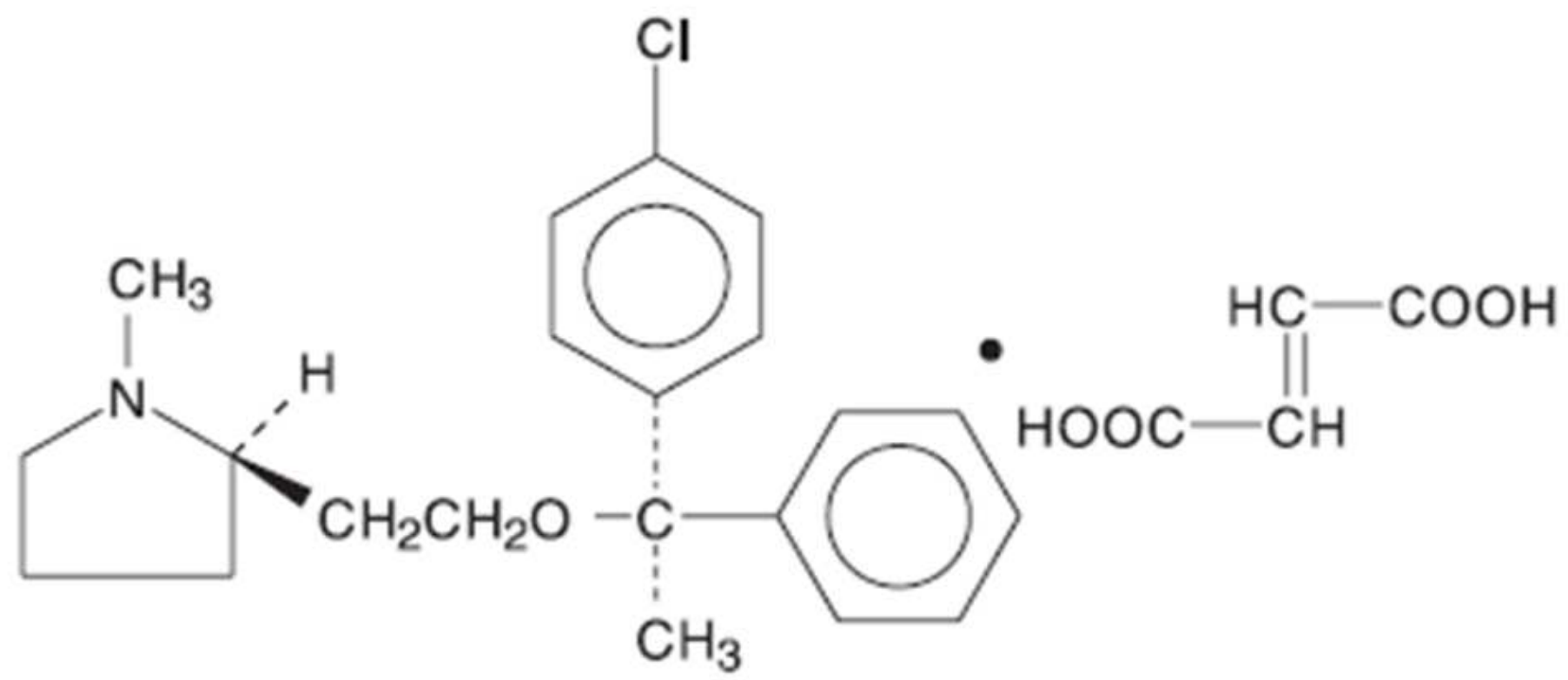

Figure 1

Chemical structure of clemastine fumarate.

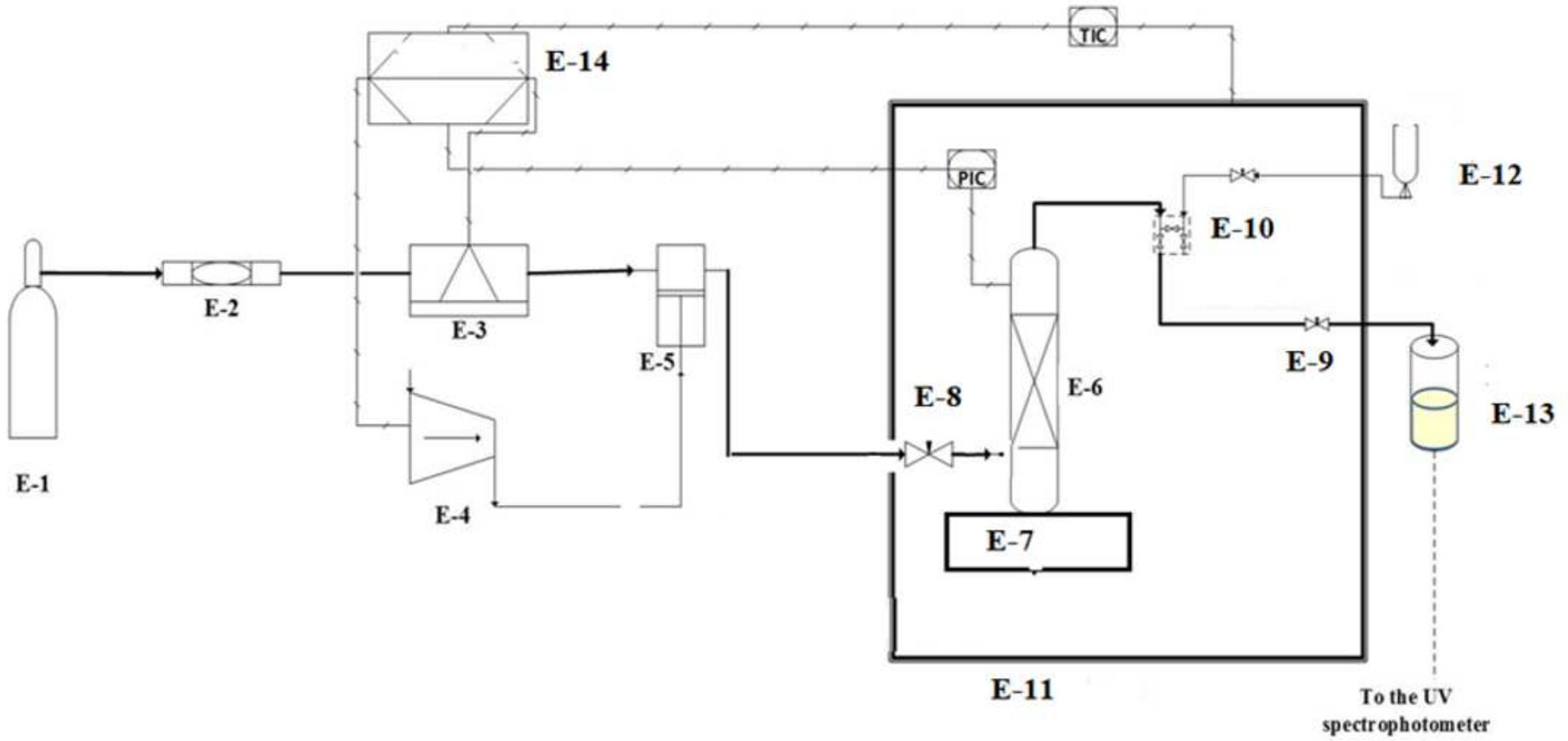

Figure 2 
Line diagram of the solubility measurement device, E1- CO2 cylinder; E-2- Filter; E-3- Refrigerator unit; E-4Air compressor; E-5- High pressure pump; E-6 Equilibrium cell; E-7- Magnetic stirrer; E-8- Needle valve; E-9-, Back-pressure valve; E-10 Six-port, two position valve; E-11- Oven; E-12-Syringe; E13- Collection vial; E-14Control panel.

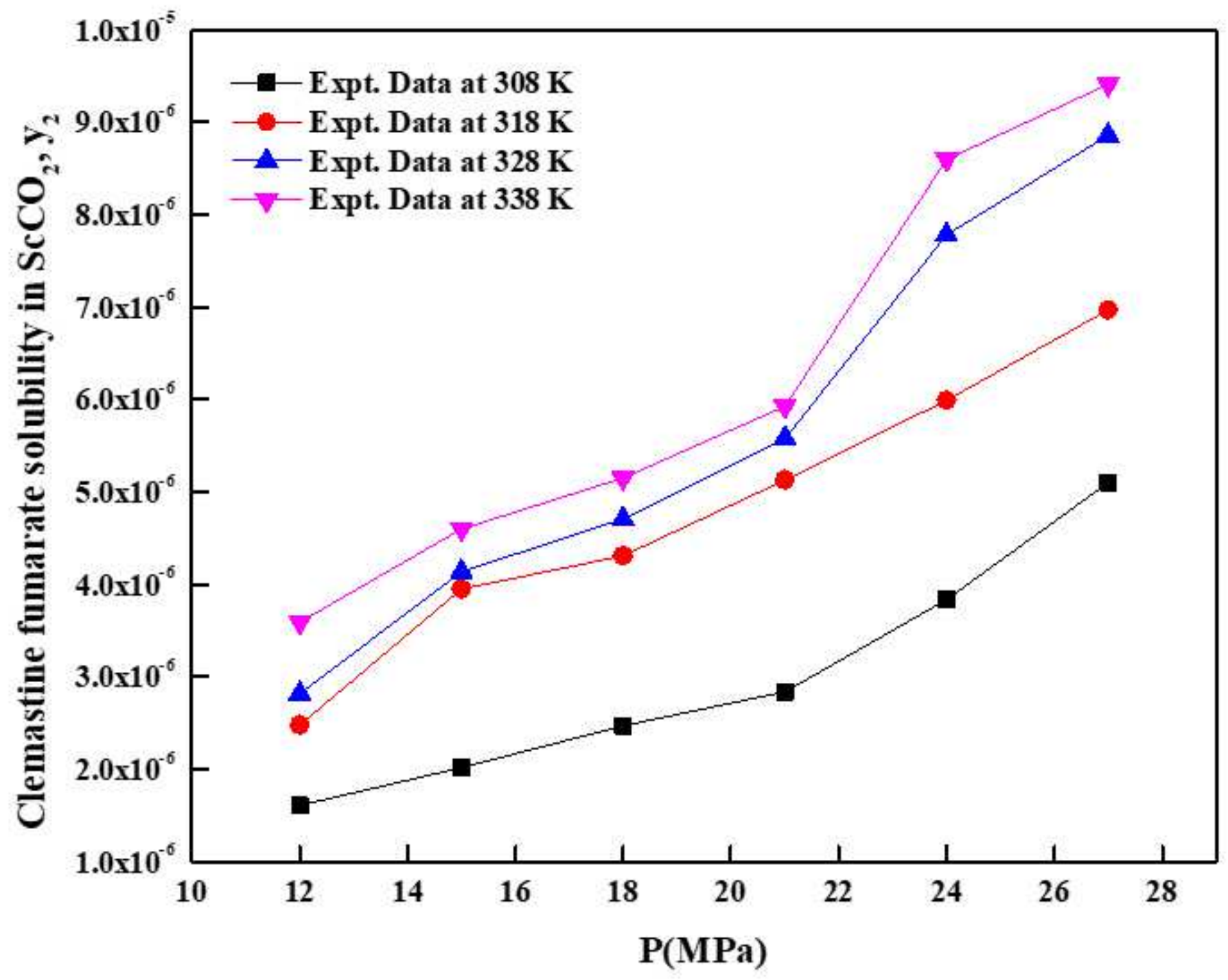

Figure 3

Clemastine fumarate solubility in ScCO2 and effect of pressure on isotherms. 


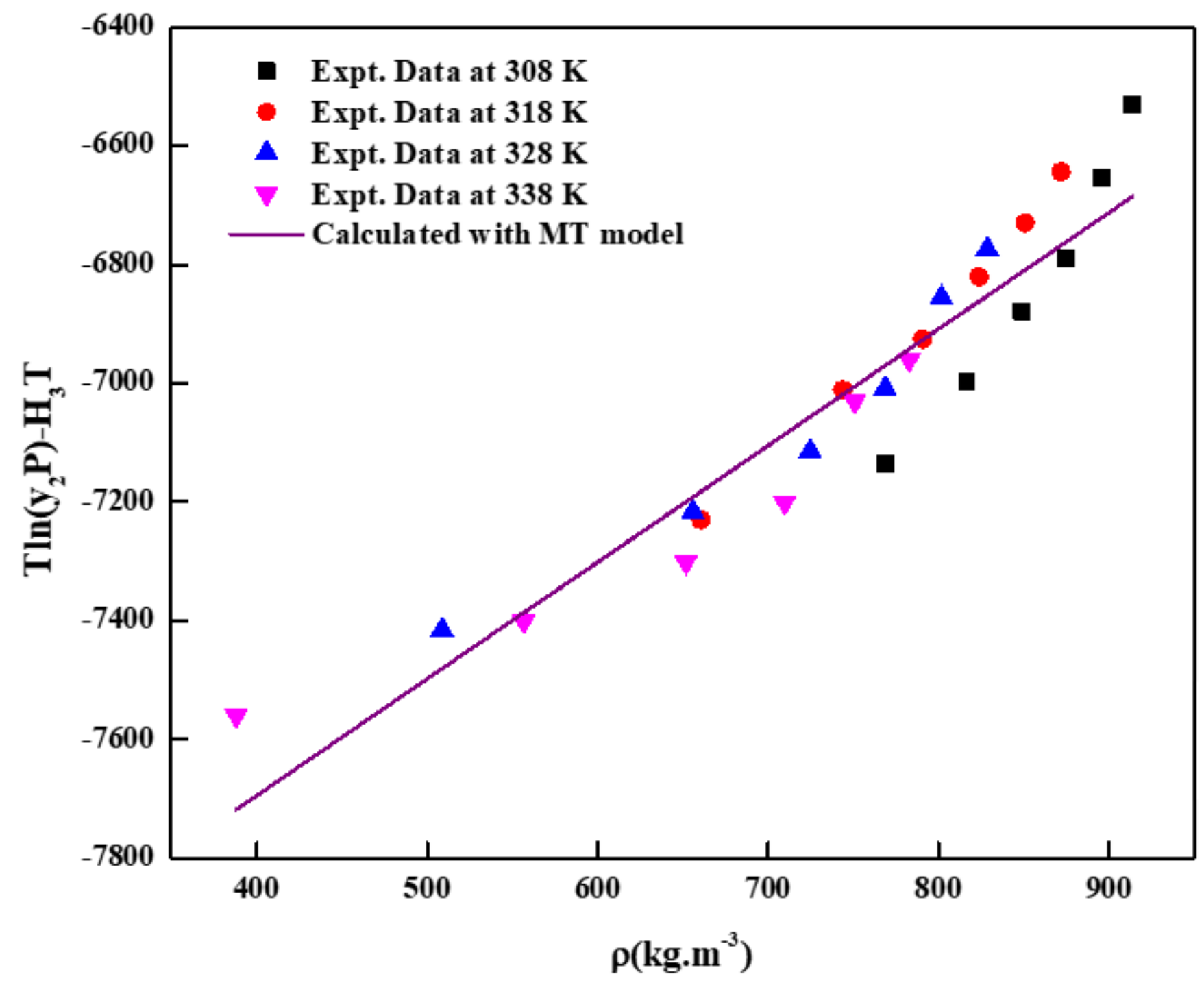

Figure 4

Self-consistency plot of clemastine fumarate solubility in ScCO2. Symbols are experimental points; line is calculated with MT Model. 


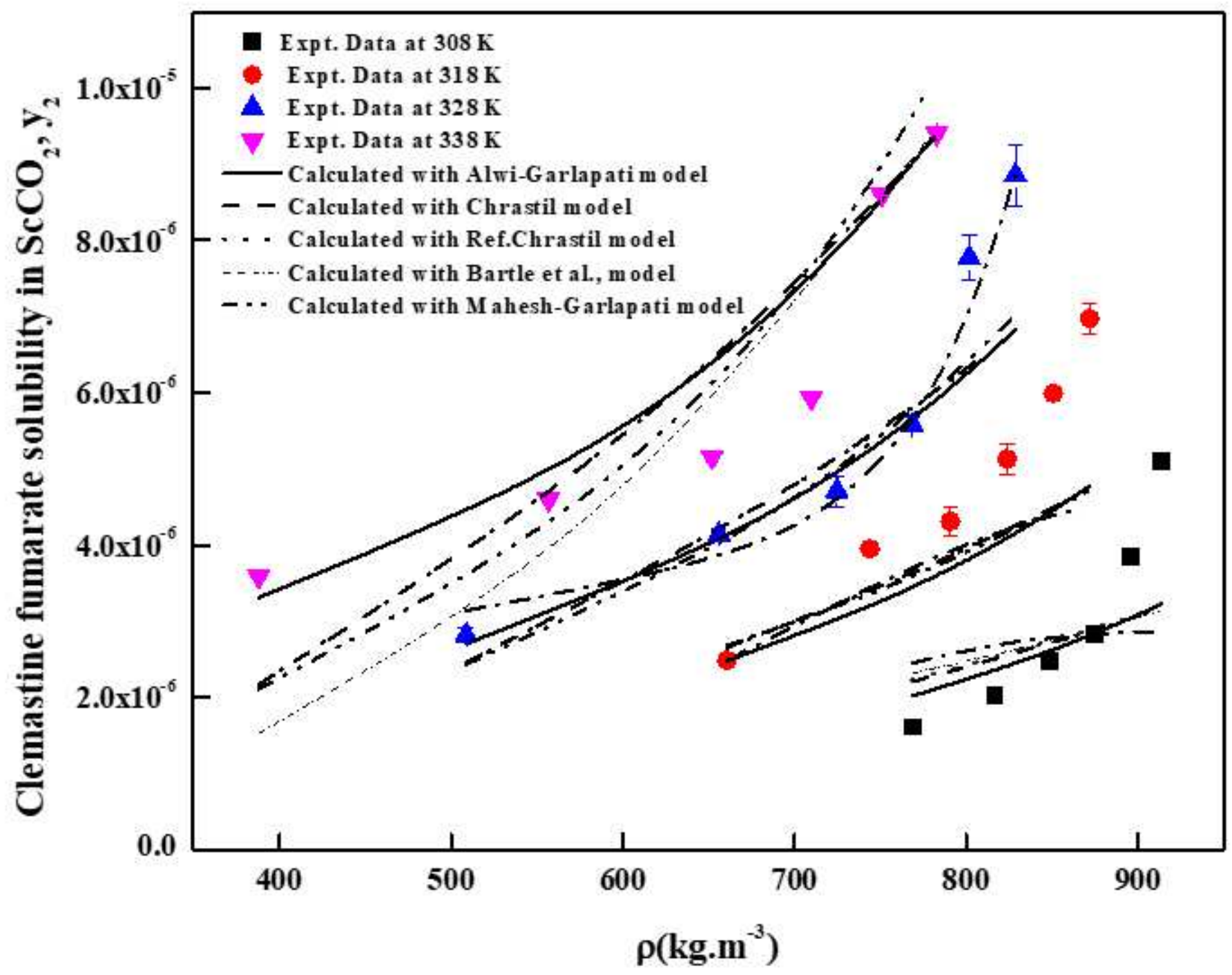

Figure 5

Solubility of clemastine fumarate in ScCO2. Symbols are experimental points; lines are calculated with three parameter models. 


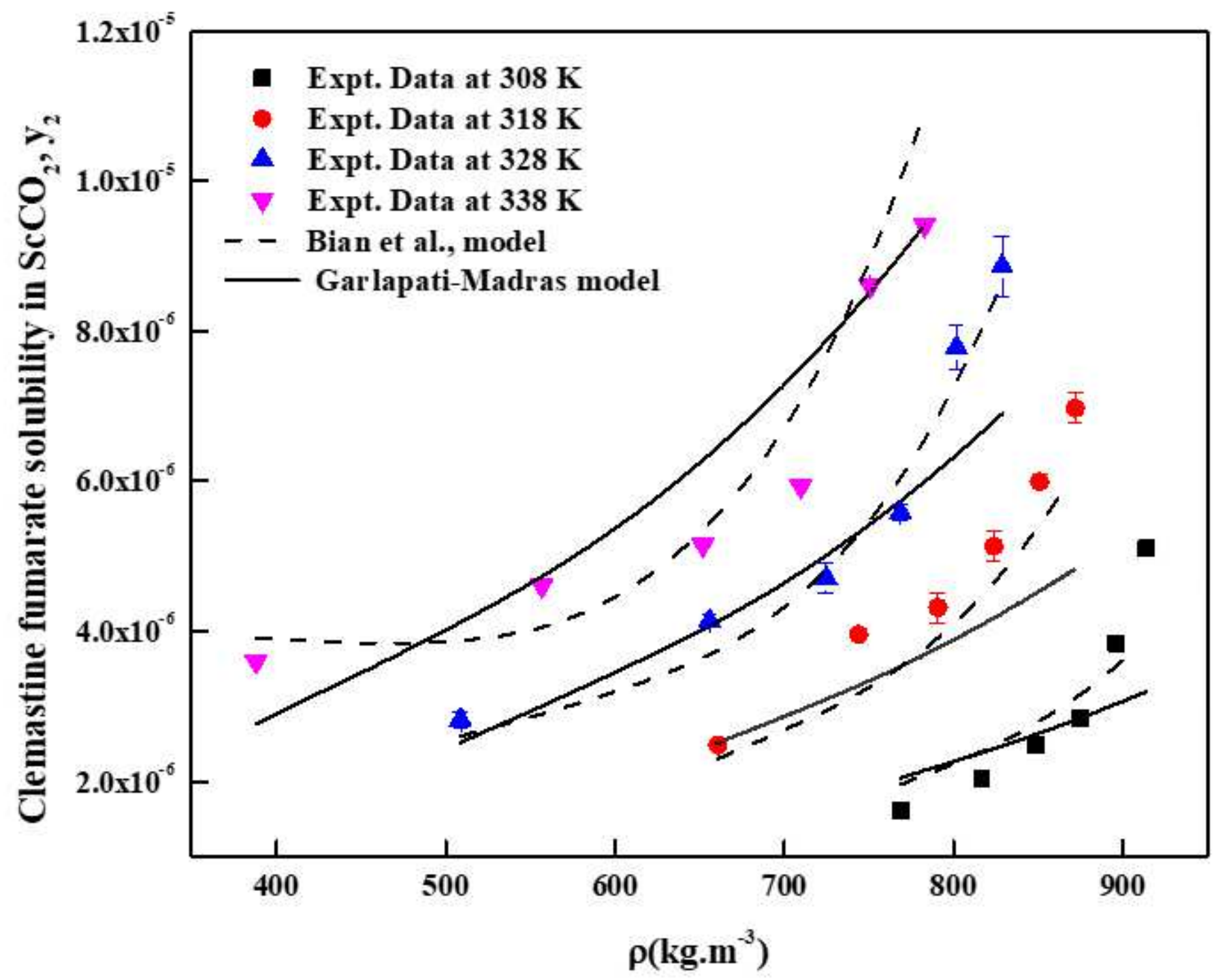

Figure 6

Solubility of clemastine fumarate in ScCO2. Symbols are experimental points; lines are calculated with five parameter models. 


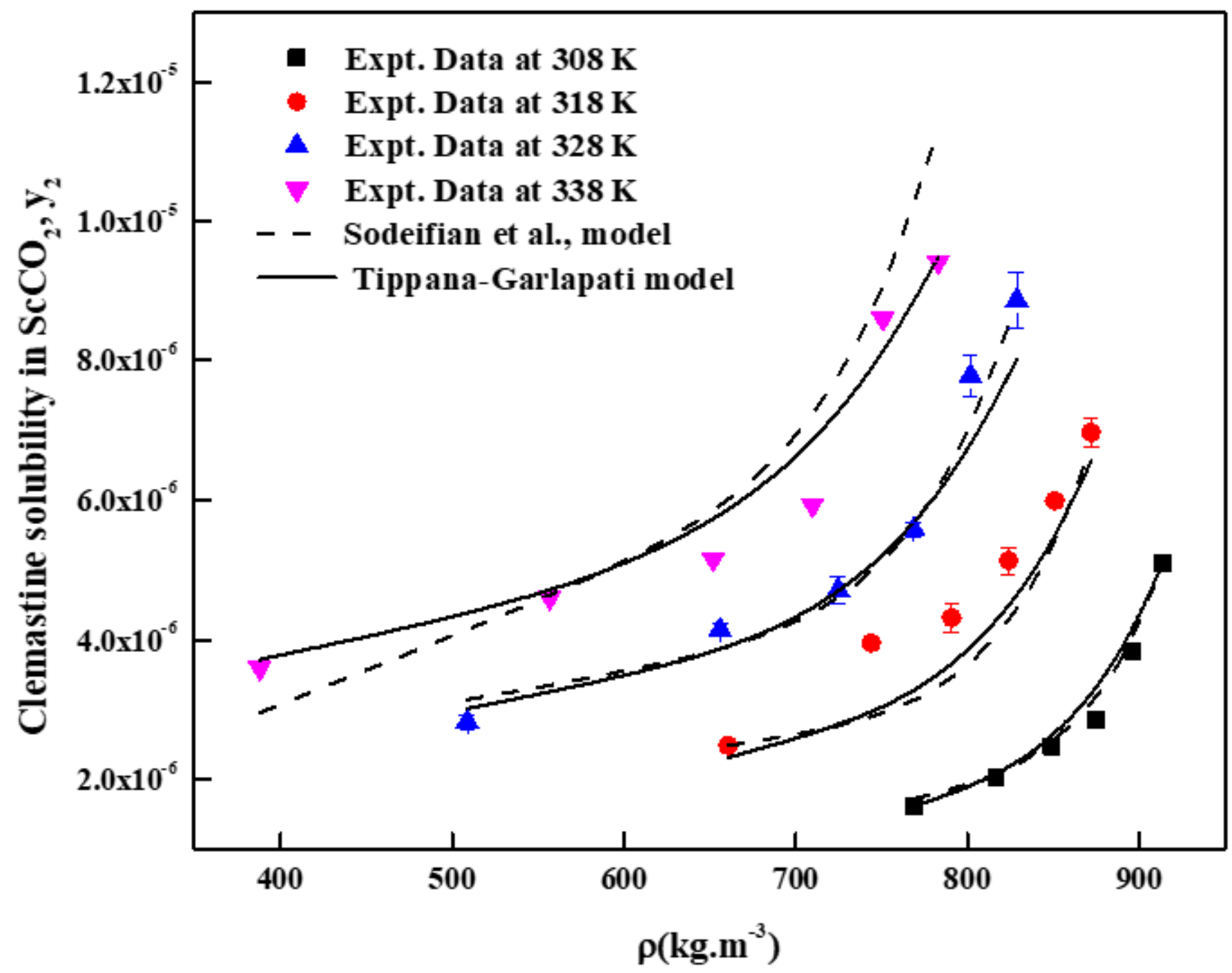

Figure 7

Solubility of clemastine fumarate in ScCO2. Symbols are experimental points; lines are calculated with six parameter models. 


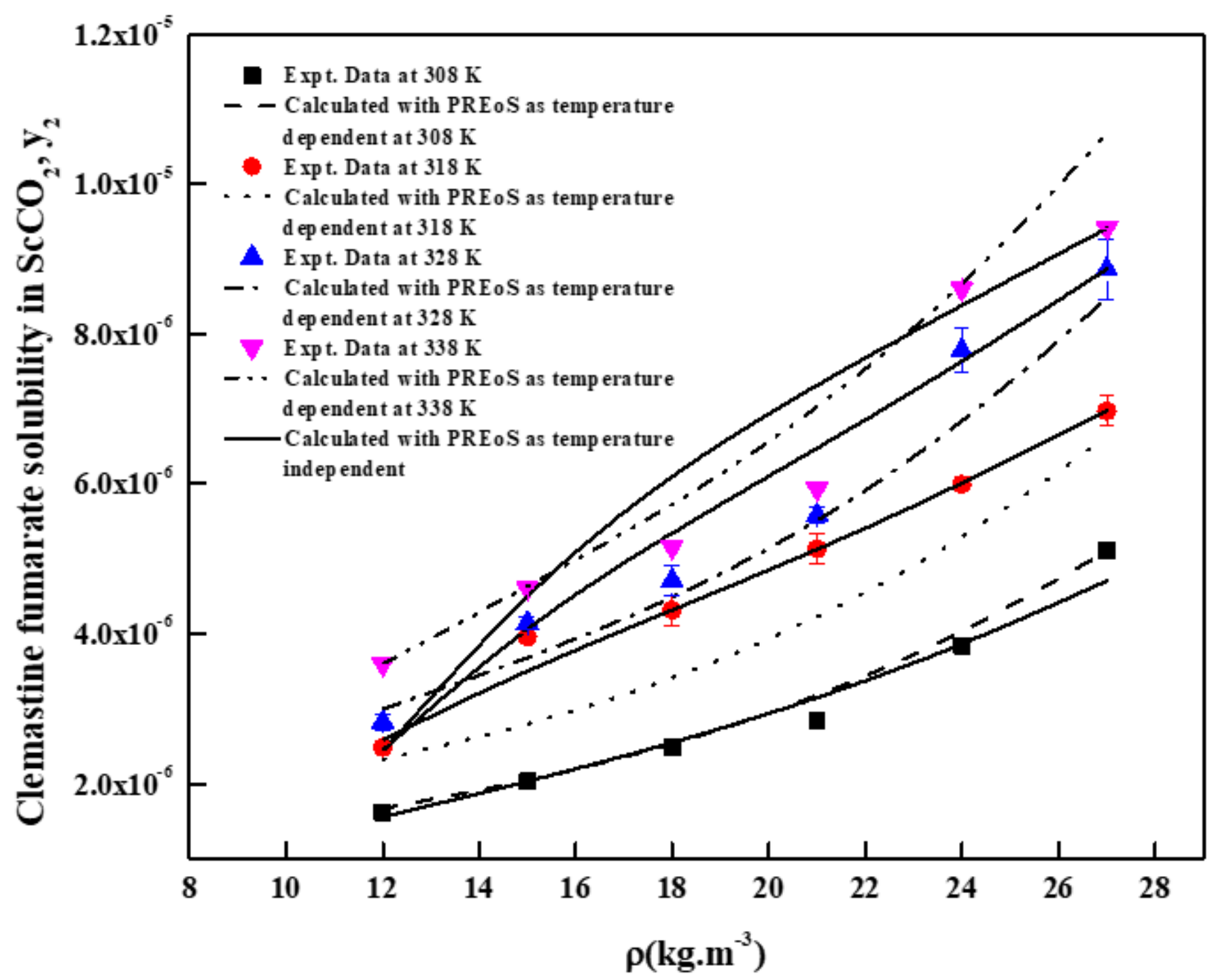

Figure 8

Solubility of clemastine fumarate in ScCO2. Symbols are experimental points; lines are calculated with PREOS models. 


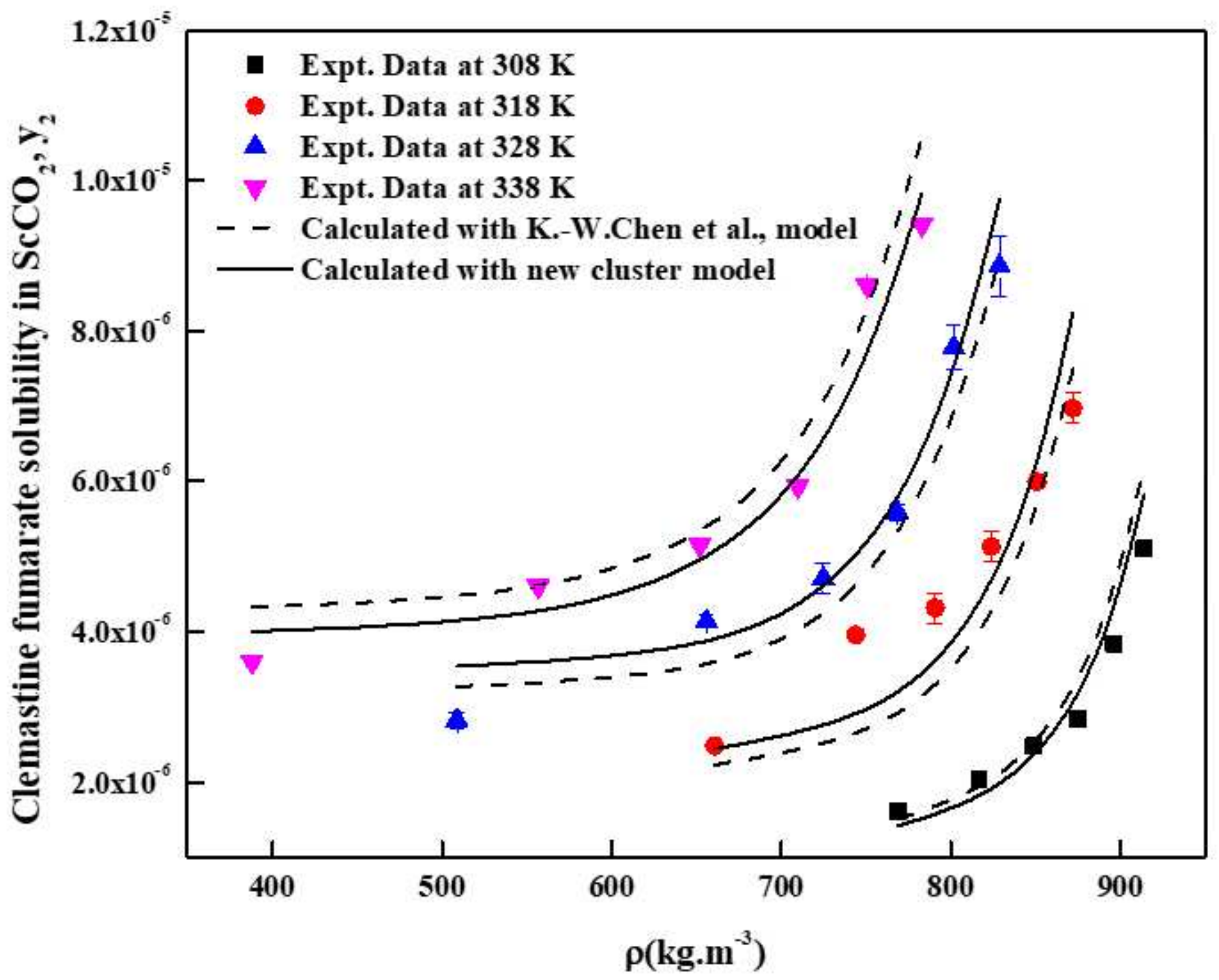

Figure 9

Solubility of clemastine fumarate in ScCO2. Symbols are experimental points; lines are calculated with cluster models.

\section{Supplementary Files}

This is a list of supplementary files associated with this preprint. Click to download.

- Tables.docx 